\title{
28 Research Square

\section{Vitamin D Status in Full-term Exclusively Breastfed Infants versus Full-term Breastfed Infants Receiving Vitamin D Supplementation in Thailand: A Randomized Controlled Trial}

Chayatat Ruangkit

Ramathibodi Hospital

Sukrit Suwannachat

Ramathibodi Hospital

Pornchanok Wantanakorn

Ramathibodi Hospital

Napapailin Sethaphanich

Ramathibodi Hospital

Surapat Assawawiroonhakarn

Ramathibodi Hospital

Oraporn Dumrongwongsiri ( $\nabla$ oraporn.roj@mahidol.ac.th )

Ramathibodi Hospital

\section{Research Article}

Keywords: 250HD, 25-hydroxyvitamin D, vitamin D deficiency, vitamin D insufficiency, vitamin D supplementation, parathyroid hormone, exclusively breastfed infants

Posted Date: March 23rd, 2021

DOl: https://doi.org/10.21203/rs.3.rs-332758/v1

License: (c) (1) This work is licensed under a Creative Commons Attribution 4.0 International License. Read Full License 


\section{Abstract}

Background: Many international medical organizations recommend vitamin D supplementation for infants, especially exclusively breastfed infants. In Thailand, however, data regarding the vitamin D status in Thai infants are lacking. Such data would help to support physician decisions and guide medical practice.

Methods: Full-term, exclusively breastfed infants were randomized into two groups at 2 months of age to continue exclusive breastfeeding either without vitamin $D$ supplementation (control group, $n=44$ ) or with vitamin $D_{3}$ supplementation at $400 \mathrm{IU} /$ day (intervention group, $n=43$ ) until 6 months of age. At 6 months, the serum vitamin D $(250 \mathrm{HD})$ of the infants and their mothers, serum bone marker, and infants' growth parameters were compared between the two groups.

Results: The infants' serum 250HD concentration was lower in the control group than intervention group $(20.57 \pm 12.66$ vs. $46.01 \pm 16.42 \mathrm{ng} / \mathrm{mL}, \mathrm{p}<0.01)$. More infants had vitamin D sufficiency $(25 \mathrm{OHD}$ of $>20$ $\mathrm{ng} / \mathrm{mL}$ ) in the intervention group than control group ( $93.0 \%$ vs. $43.2 \%, \mathrm{p}<0.01)$. Vitamin $D$ supplementation in breastfed infants increased the mean serum $250 \mathrm{HD}$ concentration by $25.66 \mathrm{ng} / \mathrm{mL}$ (95\% confidence interval, $19.07-32.25 ; p<0.001$ ) and contributed to an $88.7 \%$ decrease in the prevalence of vitamin $D$ insufficiency/deficiency (relative risk, $0.11 ; 95 \%$ confidence interval, $0.04-0.35 ; p<0.01$ ).

Conclusions: Most full-term, exclusively breastfed Thai infants have serum vitamin D concentration below sufficiency level at 6 months of age. However, vitamin D supplementation (400 IU/day) improves their vitamin $\mathrm{D}$ status and prevents vitamin $\mathrm{D}$ deficiency.

Trial registration: The study was pre-registered in the Thai Clinical Trials Registry (TCTR20190622001) on 22/06/2019.

\section{Background}

Vitamin D plays an important role in bone metabolism and affects many extraskeletal organ systems (1). Severe vitamin $D$ deficiency may cause rickets in infants or children and osteomalacia in adults. The natural production of vitamin $D$ in the skin through sunlight exposure is the primary source of vitamin $D$ in humans. Direct dietary vitamin D intake from natural foods, fortified foods, and supplements is another source of vitamin D for the body. Despite improved nutritional knowledge and medical care, vitamin D deficiency and infantile rickets remain significant global public health challenges in developed and developing countries $(2,3)$

During the first year of life, breastfeeding is one of the most critical factors to child survival, nutrition, development, and maternal health. The World Health Organization and the United Nations Children's Fund recommend that infants should be exclusively breastfed for the first 6 months of life (4). However, breastfed infants are known to be at risk of vitamin D deficiency, especially in areas of high latitude, because the vitamin $D$ content in breast milk can vary depending on the maternal vitamin $D$ status and is 
often low $(5,6)$. Moreover, infants' exposure to sunlight may be limited because of their geographical location; their parents' culture, beliefs, or practices; or other reasons. As a result, many international medical organizations, including the American Academy of Pediatrics, recommend vitamin D supplementation for infants, especially those who are exclusively breastfed $(7,8)$. Despite these international recommendations, adherence to the guidelines is still problematic in many countries $(9,10)$. Previous studies have revealed barriers to vitamin D supplementation in infants, including physicians' beliefs that infants in their geographic area are exposed to adequate sunlight or that breast milk provides sufficient vitamin $D$, making supplementation unnecessary (11).

In Thailand, routine vitamin D supplementation for exclusively breastfed infants has not been widely practiced. Reasons for this include physicians' belief that infants' vitamin D status is adequate without supplementation, the lack of obvious clinical signs of vitamin D deficiency during the exclusive breastfeeding period, and the difficulty finding suitable vitamin D preparations in Thailand. Most importantly, the local healthcare authorities have not established a national consensus to guide pediatricians on vitamin D supplementation in infants. Currently, data on the vitamin D status among breastfed infants in Thailand are very scarce. There is not enough evidence to establish a guideline to support physician decisions or guide medical practice; therefore, research in this field is urgently needed.

This study was performed to evaluate the effect of vitamin D supplementation on the vitamin D status of exclusively breastfed infants during the first 6 months of life. In addition, the associations among the vitamin D status, serum bone markers, and growth parameters of infants were evaluated.

\section{Methods}

This open-label randomized controlled trial was conducted at Chakri Naruebodindra Medical Institute, Faculty of Medicine Ramathibodi Hospital, Mahidol University, Samut Prakan, Thailand from July 2019 to October 2020. The study protocol was approved by the Ramathibodi Hospital Institutional Review Board (ID 10-61-58). The study was pre-registered in the Thai Clinical Trials Registry (TCTR20190622001) on $22 / 06 / 2019$.

\section{Study population and randomization}

The study participants were recruited from healthy full-term infants and their mothers who attended the well-baby clinic at Chakri Naruebodindra Medical Institute for a routine 2-month infant checkup and immunization. To be eligible, the infants were required to be 6 to 12 weeks old when they entered the study. Only mothers who performed exclusive breastfeeding and had an intention to continue exclusive breastfeeding until the infants were 6 months old were approached for their consent to participate in the trial. The exclusion criteria were premature infants with a gestational age of $<37$ weeks at birth, infants with a congenital anomaly, introduction of formula milk and/or complementary foods before 6 months of age, and participant withdrawal. After the mothers had provided informed consent, the infants were randomized into two groups: the control group and the intervention group. Randomization was performed using opaque, sealed, sequentially numbered envelopes opened after informed consent. Each envelope 
contained a computer-generated block of four intervention order randomization assignments. An enrollment log was kept to ensure all envelopes were accounted for and used in the correct order.

\section{Intervention}

Routine health supervision and immunization were provided to both groups of participants under individualized physician discretion. Infants in the intervention group were given $400 \mathrm{mg} /$ day of vitamin D supplementation ( $400 \mathrm{mg} /$ day) in the form of a daily 1-mL multivitamin drop (composition per $\mathrm{mL}$ : vitamin $A, 2000 \mathrm{IU}$; vitamin $\mathrm{B}_{1}, 2$ mg; vitamin $\mathrm{B}_{2}, 2$ mg; vitamin $\mathrm{B}_{6}, 1.8 \mathrm{mg}$; vitamin $\mathrm{B}_{12}, 5$ mcg; vitamin $\mathrm{C}$, 40 mg; vitamin $\mathrm{D}_{3}, 400 \mathrm{lU}$; nicotinamide, $15 \mathrm{mg}$; dexpanthenol) (Munti-Vim drops; B.L. Hua \& Co., Ltd., Bangkok, Thailand). The multivitamin drop was used in the study because there was no commercially available infant vitamin D-only preparation in Thailand at the time of the study. No placebo was given to the infants in the control group.

At 4 months of age, follow-up appointments were made for all infants to ensure compliance with the study protocol and to refill the vitamin D supplementation in the intervention group. At 6 months of age, follow-up appointments were made for all infants and their mothers to conclude the study and collect blood samples. Both appointments at 4 and 6 months of age were performed in accordance with the infants' routine checkup and immunization schedule visits.

\section{Data collection}

The infants' demographic data (place of birth, season at birth, gestational age, and sex) and anthropometric data (weight, length, and head circumference) at birth and at the 2-month visit were collected at the time of study enrollment. At the 4- and 6-month visits, the infants' anthropometric measurements were repeated. At the 6-month visit, the following laboratory data were obtained for each infant: serum concentrations of vitamin $\mathrm{D}$ [25-hydroxyvitamin $\mathrm{D}_{2}\left(25 \mathrm{OHD} \mathrm{D}_{2}\right)$, 25-hydroxyvitamin $\mathrm{D}_{3}$ $\left(25 \mathrm{OHD}_{3}\right)$, and total 25-hydroxyvitamin (25OHD)], intact parathyroid hormone (iPTH), calcium, phosphorous, and alkaline phosphatase (ALP). Maternal age and serum vitamin D concentrations were also collected at the 6-month visit.

\section{Biochemical analyses}

Serum vitamin $\mathrm{D}\left(25 \mathrm{OHD}_{2}, 250 \mathrm{HD}_{3}\right.$, and $\left.250 \mathrm{HD}\right)$ was analyzed using liquid chromatography-tandem mass spectrometry assays (6490 Triple Quad LC/MS; Agilent Technologies, Santa Clara, CA, USA). The iPTH concentration was measured using an electrochemiluminescence immunoassay (cobas e601; Roche Diagnostics, Basel, Switzerland). The plasma concentrations of calcium, phosphorous, and ALP were measured using an automated analyzer (cobas c501; Roche Diagnostics). Vitamin D deficiency was defined as a $250 \mathrm{HD}$ concentration of $<12 \mathrm{ng} / \mathrm{mL}$, insufficiency as $250 \mathrm{HD}$ of 12 to $20 \mathrm{ng} / \mathrm{mL}$, and sufficiency as $250 \mathrm{HD}$ of $>20 \mathrm{ng} / \mathrm{mL}$ (8).

\section{Sample size estimation}


A power calculation was used to calculate the sample size needed to evaluate the primary outcome (infants' 250HD concentrations). A pilot study of 34 full-term, exclusively breastfed infants aged 1 to 6 months in our institution (Ramathibodi Hospital, Bangkok) showed that the infants' mean 250HD concentration was $13.6 \pm 7.7 \mathrm{ng} / \mathrm{mL}$ (unpublished data). We hypothesized that vitamin $\mathrm{D}$ supplementation would increase the $250 \mathrm{HD}$ level by at least $50 \%$ in the intervention group or to a mean $250 \mathrm{HD}$ concentration of up to $20.4 \mathrm{ng} / \mathrm{mL}$ (sufficiency level) with a standard deviation similar to that in the control group. According to this assumption, 40 infants in each group were required to detect a postintervention difference in the $250 \mathrm{HD}$ concentration with an alpha of $0.01,90 \%$ power, two-sided. To allow for attrition, an additional $20 \%$ or 10 subjects were added to each group. Therefore, 50 was selected as the total number of infants in each group.

\section{Statistical analysis}

A univariate analysis was performed to identify significant differences between the groups. Student's ttest was used for continuous variables, and the results are presented as mean \pm standard deviation. The Mann-Whitney $U$ test was used if the distribution was not normal, and the results are presented as median (interquartile range). Pearson's chi-square test or Fisher's exact test was used for categorical variables, and the results are presented as total number (\%). Multivariate linear regression analysis was used to determine the factors associated with infants' 250HD concentration. To demonstrate the differences in serum bone markers between infants with and without vitamin $D$ sufficiency, univariate analysis was applied using an infant serum $250 \mathrm{HD}$ concentration of $<20 \mathrm{ng} / \mathrm{mL}$ as the independent variable. A p-value of $<0.05$ was considered statistically significant. Stata Statistical Software version 15.1 (StataCorp LLC, College Station, TX, USA) was used for all statistical analyses.

\section{Results}

One hundred mother-infant pairs were randomized to the control and intervention groups according to the study protocol. At the end of the study, 44 and 43 mother-infant pairs in the control and intervention groups, respectively, had completed the study. Figure 1 shows the number of study participants and the reasons for exclusion. The mean age of the infants at the time of enrollment and the end of the study were comparable between the control and intervention groups ( $65 \pm 4$ vs. $67 \pm 6$ days, $p=0.07$ and $184 \pm$ 4 vs. $184 \pm 4$ days, $p=0.86$, respectively).

The infants' weight at birth and enrollment was slightly lower in the intervention group than in the control group. There were no significant differences in the other baseline characteristics of the mothers and infants between the two groups. The demographic data and infants' birthing season are shown in Table 1.

At 6 months, the mean 250HD concentration was lower in the control group than intervention group ( $20.57 \pm 12.66$ vs. $46.01 \pm 16.42 \mathrm{ng} / \mathrm{mL}, \mathrm{p}<0.01)$, as shown in Table 2 . The prevalences of vitamin $D$ insufficiency and deficiency were lower among infants in the intervention group. Serum bone markers, including calcium, phosphorus, ALP, and iPTH, as well as infants' growth parameters, were comparable 
between the two groups. No infants in the study had a clinical manifestation of vitamin D toxicity or clinical rickets.

The mean $250 \mathrm{HD}$ concentration of all lactating women in the study was $24.43 \pm 7.64 \mathrm{ng} / \mathrm{mL}$. The maternal $250 \mathrm{HD}$ concentrations were not different between the two groups $(25.08 \pm 7.75$ vs. $23.75 \pm 7.64$ $\mathrm{ng} / \mathrm{mL}$, respectively; $\mathrm{p}=0.42$ ). The overall prevalence of vitamin $D$ insufficiency and deficiency among lactating women was $27.6 \%$ (24 of 87 ) and $2.3 \%$ ( 2 of 87 ), respectively. There was no difference in the prevalence of vitamin $D$ insufficiency and deficiency in lactating women between the two groups (Table 2).

Multivariate linear regression analysis, which included the study group (control or intervention), maternal $250 H D$ concentration, infants' age, weight at enrollment, sex, and birth season, showed that vitamin $D$ supplementation increased the infants' mean $250 \mathrm{HD}$ concentration by $25.66 \mathrm{ng} / \mathrm{mL}$ [95\% confidence interval (Cl), 19.07-32.25); $\mathrm{p}<0.001]$. The model also showed the association of the maternal and infants' $250 \mathrm{HD}$ concentrations ( $\beta=0.52 ; 95 \% \mathrm{Cl}, 0.11-0.94 ; p=0.013$ ) independent of whether the infants were receiving vitamin $D$ supplementation. Other factors were not significant predictors of the infants' $250 H D$ concentration. In addition, the binary regression model showed that vitamin D supplementation reduced vitamin $\mathrm{D}$ insufficiency and deficiency by $88.7 \%$ (relative risk, $0.11 ; 95 \% \mathrm{Cl}$, $0.04-0.35 ; p<0.01)$.

The associations between serum bone markers and infants' vitamin D status were analyzed, as shown in Table 3. The iPTH concentration was $13.72 \mathrm{pg} / \mathrm{mL}$ higher in infants with a $250 \mathrm{HD}$ concentration of $<20$ $\mathrm{ng} / \mathrm{mL}$ than in those with a normal $250 \mathrm{HD}$ concentration. No associations were found between other serum bone markers and infants' vitamin $\mathrm{D}$ status.

\section{Discussion}

This is the first study in Thailand to compare the vitamin D status of breastfed infants with and without vitamin D supplementation during the exclusive breastfeeding period. Vitamin D supplementation increased the $250 \mathrm{HD}$ concentration and decreased the prevalence of vitamin D insufficiency and deficiency in breastfed infants. We found that the 250HD concentration among unsupplemented breastfed infants was low and that fewer than half had vitamin D sufficiency. In addition, we found that approximately $30 \%$ of lactating women had serum vitamin D concentration below sufficiency level.

Limited data are available on the vitamin D status in breastfed infants in Thailand. The mean 250HD concentration in unsupplemented breastfed infants in our study was comparable with that in breastfed infants born in summer in Greece $(19.4 \pm 2.8 \mathrm{ng} / \mathrm{ml})(12)$. The Greece study also showed a significantly higher 250HD concentration in infants born in summer than in winter. In contrast to countries located in the northern and southern hemispheres with marked seasonal variations in weather, especially in summer and winter, Thailand has only three seasons with relatively abundant sunlight all year round. This may explain the lack of a significant association of infants' birth season with the serum vitamin $D$ concentration. Our study showed that unless they were receiving vitamin D supplementation, $56.8 \%$ of 
breastfed infants at 6 months of age had serum vitamin D concentration below sufficiency level. The prevalence of vitamin $D$ insufficiency or deficiency among infants in tropical countries was previously expected to be low because of the large amount of sunlight in these areas. The prevalences of vitamin $D$ insufficiency and deficiency ( $\leq 20 \mathrm{ng} / \mathrm{mL}$ ) among unsupplemented breastfed infants in the present study are comparable with those reported in Hong Kong (60\%) (13). The prevalences were lower than those reported in India (90\%) (14), Taiwan (86.1\%) (15), Qatar (83\%) (16), and Japan (76.9\%) (17) but higher than those in Boston, MA, USA (40\%) (18), Kenya (23.4\%) (19), and Indonesia (16.7\%) (20). The variation in these reported prevalences was likely caused by multiple factors, such as the infants' age, ethnicity, geographical location, and study methodology. Interestingly, an Indonesian study revealed much lower prevalences of vitamin $D$ insufficiency and deficiency than in the present study despite the fact that Indonesia and Thailand are located at similar latitudes in the Southeast Asia region. The authors described the traditional morning sunbathing practice in the study area, which might be one of the factors that contributed to the relatively high serum vitamin $D$ concentration among the infants in this area (20).

Our results showed that $400 \mathrm{IU}$ of vitamin D supplementation daily increased the serum $250 \mathrm{HD}$ concentration and contributed to an $88 \%$ reduction in the prevalences of vitamin $D$ insufficiency and deficiency among breastfed infants. Our findings are consistent with previous studies that showed low prevalences of vitamin D deficiency and insufficiency $(\leq 20 \mathrm{ng} / \mathrm{mL})$ when exclusively breastfed infants were supplemented with $400 \mathrm{IU}$ of vitamin D daily $(21,22,23)$. A recent systematic review determined the effect of vitamin D supplementation in breastfed infants compared with placebo (24). The authors found six and four randomized controlled trials that determined the primary outcome of infants' vitamin $D$ concentration and vitamin D status, respectively. This systematic review indicated that vitamin $D$ supplementation at $400 \mathrm{IU} /$ day for breastfed infants may increase the serum $250 \mathrm{HD}$ concentration and reduce the incidence of vitamin $D$ insufficiency. However, the study was unable to confirm the benefits of vitamin $D$ supplementation on vitamin $D$ deficiency, the bone mineral content, the incidence of biochemical or radiological rickets, and the risk of detrimental effects in infants.

Serum bone markers, including iPTH and ALP, were not different between the control and intervention groups in our study. However, we found that the serum iPTH concentration was $13.7 \mathrm{pg} / \mathrm{mL}$ higher in infants with vitamin D deficiency and insufficiency $(\leq 20 \mathrm{ng} / \mathrm{mL})$ than in those with vitamin D sufficiency. This finding indicates the effect of vitamin $D$ deficiency on infants' bone health.

There is a concern regarding vitamin $D$ toxicity while giving vitamin $D$ supplements to infants. No infants in our study had a serum $250 \mathrm{HD}$ concentration of $>100 \mathrm{ng} / \mathrm{mL}$, the level regarded as toxicity (8). Our study also showed that serum calcium and phosphorus were not higher in the intervention group than in the control group. This finding is consistent with a recent systematic review regarding vitamin $D$ supplementation in breastfed infants (25).

The vitamin D concentration and prevalences of vitamin D insufficiency and deficiency among the lactating women in our study were comparable with the results of a previous study from Thailand, which reported a mean vitamin $D$ concentration of $24.64 \pm 7.72 \mathrm{ng} / \mathrm{mL}$ at delivery; concentrations of $<20 \mathrm{ng} / \mathrm{mL}$ 
were found in $34.0 \%$ of women (26). Vitamin D insufficiency and deficiency in lactating women have been reported in many parts of the world. A global study showed that the mean vitamin $D$ concentration was $28.08 \mathrm{ng} / \mathrm{mL}$ in Cincinnati, $19.44 \mathrm{ng} / \mathrm{mL}$ in Shanghai, and $19.28 \mathrm{ng} / \mathrm{mL}$ in Mexico City. Vitamin D concentrations of $<20 \mathrm{ng} / \mathrm{mL}$ were found at 4 weeks postpartum in $17 \%, 52 \%$, and $62 \%$ of mothers in Cincinnati, Shanghai, and Mexico City, respectively (27). The vitamin D status of lactating women should be a topic of concern because it affects the vitamin D status in breastfed infants, as shown in our study. The maternal vitamin $D$ status during pregnancy is directly correlated with the fetal and neonatal vitamin D status, and this relationship continues during lactation (28).

To the best of our knowledge, this is the first study in Thailand to investigate the vitamin D status in exclusively breastfed infants and lactating women and to evaluate the effect of breastfed infants' vitamin D supplementation on the vitamin D status in these infants. At the time of our study, there was no official national guideline regarding vitamin $D$ supplementation in healthy infants. Routine vitamin $D$ supplementation for exclusively breastfed infants has not been widely practiced by the pediatricians and general physicians who provide care for the children in the community, possibly because of lack of guidance and supporting evidence specific to the Thai population. This facilitated performance of the present randomized controlled trial, in which infants in the control group were not given vitamin D supplementation. As increasing evidence worldwide indicates the universal presence of vitamin $D$ deficiency in exclusively breastfed infants, and once the international medical community's authorities acknowledge the global recommendation, future studies performed in a similar fashion would likely be considered unethical.

This study has some limitations. This was an open-label study without a placebo in the control group, which could have led to bias. However, several measures were used to reduce bias, including blinding the infants' growth assessment personals from the group allocation and targeting the objective outcome measurements. Compliance with the protocol was based solely on the parents' interview, which could have been inaccurate. Some parents might have provided infant formula or complementary food to the infants without disclosure to the study team. The infants' baseline vitamin D concentrations were not assessed in our trial; however, the infants' baseline characteristics in both groups were comparable. Most participants in this study lived in Samut Prakan province, a city located on the outskirts of Bangkok. Therefore, the data may not represent populations in other areas of Thailand.

\section{Conclusions}

Although Thailand is located in the tropical climate zone and has relatively abundant sunlight all year round, vitamin D insufficiency is not uncommon in nursing mothers and infants in Thailand. Almost onethird of lactating mothers and more than half of full-term, exclusively breastfed infants at 6 months of age have serum vitamin D concentrations below sufficiency level. However, vitamin D supplementation (400 IU/day) for these infants improves their vitamin D status and prevents vitamin D deficiency.

\section{Abbreviations}


ALP: alkaline phosphatase

iPTH: intact parathyroid hormone

25OHD 2 : 25-hydroxyvitamin $\mathrm{D}_{2}$

$25 \mathrm{OHD}_{3}: 25$-hydroxyvitamin $\mathrm{D}_{3}$

25OHD: total 25-hydroxyvitamin D

Cl: confidence interval

\section{Declarations}

\section{Ethics approval and consent to participate}

The study protocol was approved by the Ramathibodi Hospital Institutional Review Board (ID 10-61-58). Individual informed consent of the mother and their infant in the study was obtained from the mother prior to participating in a trial. All the experiment protocol involving humans subjects was in accordance with the institutional ethical standards and the Helsinki Declaration.

\section{Consent for publication}

Not applicable

\section{Availability of data and materials}

The datasets used and/or analysed during the current study are available from the corresponding author on reasonable request.

\section{Competing interests}

The authors declare no conflict of interest.

\section{Funding}

This study was supported by the Ramathibodi Hospital research fund (RF_62054) and the Thai Breastfeeding Center Foundation research fund.

\section{Authors' contributions}

$\mathrm{CR}$ and OD designed the study. OD prepared the randomization sequence. CR, SS, PW, NS, and SA performed the subject recruitment, intervention group assignment, follow-up, and data collection. OD analyzed the data. CR drafted the original manuscript. OD revised the final manuscript and supervised the overall project. All authors read and approved the final manuscript. 
We thank the mothers and their infants who participated in our study. We especially thank the nursing staff and nursing aides of the Well Child Clinic at Chakri Naruebodindra Medical Institute for their assistance in patient recruitment and follow-up. Furthermore, we would like to extend our sincere gratitude to the interns, pediatric hospitalists, and attending staff at Chakri Naruebodindra Medical Institute for their help and support during the study period. We would like to thank Ms. Sasiporn Sitthisorn and Assoc. Prof. Sasivimol Rattanasiri for their guidance in the statistical analysis. Finally, we are grateful to Prof. Somneuk Sungkanuparph, M.D. for reviewing our manuscript and providing valuable suggestions.

\section{References}

1. Bouillon R, Marcocci C, Carmeliet G, Bikle D, White JH, Dawson-Hughes B, et al. Skeletal and extraskeletal actions of vitamin D: Current evidence and outstanding questions. Endocr Rev. 2019;40(4):1109-51. doi:10.1210/er.2018-00126

2. Balasubramanian $S$. Vitamin $D$ deficiency in breastfed infants \& the need for routine vitamin $D$ supplementation. Indian J Med Res. 2011;133:250-2.

3. Creo AL, Thacher TD, Pettifor JM, Strand MA, Fischer PR. Nutritional rickets around the world: an update. Paediatr Int Child Health. 2017 May;37(2):84-98. doi:10.1080/20469047.2016.1248170

4. World Health Organization, UNICEF. Global strategy for infant and young child feeding. whqlibdoc.who.int/publications/2003/9241562218.pdf (accessed 25 December 2020).

5. Dawodu A, Tsang RC. Maternal vitamin D status: effect on milk vitamin D content and vitamin $D$ status of breastfeeding infants. Adv Nutr. 2012;3(3):353-61. doi:10.3945/an.111.000950

6. Stoutjesdijk E, Schaafsma A, Nhien NV, Khor GL, Kema IP, Hollis BW, et al. Milk vitamin D in relation to the "adequate intake" for 0-6-month-old infants: a study in lactating women with different cultural backgrounds, living at different latitudes. Br J Nutr. 2017;118(10):804-12. doi:10.1017/S000711451700277X

7. Wagner CL, Greer FR, American Academy of Pediatrics Section on Breastfeeding, American Academy of Pediatrics Committee on Nutrition. Prevention of rickets and vitamin D deficiency in infants, children, and adolescents. Pediatrics. 2008;122(5):1142-52. doi:10.1542/peds.2008-1862

8. Munns CF, Shaw N, Kiely M, Specker BL, Thacher TD, Ozono K, et al. Global consensus recommendations on prevention and management of nutritional rickets. J Clin Endocrinol Metab. 2016;101(2):394-415. doi:10.1210/jc.2015-2175

9. Uday S, Kongjonaj A, Aguiar M, Tulchinsky T, Högler W. Variations in infant and childhood vitamin D supplementation programmes across Europe and factors influencing adherence. Endocr Connect. 2017;6(8):667-75. doi:10.1530/EC-17-0193

10. Simon AE, Ahrens KA. Adherence to vitamin D intake guidelines in the United States. Pediatrics. 2020;145(6):e20193574. doi:10.1542/peds.2019-3574 
11. Sherman EM, Svec RV. Barriers to vitamin D supplementation among military physicians. Mil Med. 2009;174(3):302-7. doi:10.7205/milmed-d-01-4708

12. Challa A, Ntourntoufi A, Cholevas V, Bitsori M, Galanakis E, Andronikou S. Breastfeeding and vitamin D status in Greece during the first 6 months of life. Eur J Pediatr. 2005;164(12):724-9. doi:10.1007/s00431-005-1757-1

13. Chan KC, Tam WH, Chan MH, Chan RS, Li AM. Vitamin D deficiency among healthy infants in Hong Kong: a pilot study. Hong Kong Med J. 2018;24 Suppl 3(3):32-5.

14. Meena P, Dabas A, Shah D, Malhotra RK, Madhu SV, Gupta P. Sunlight exposure and vitamin D status in breastfed infants. Indian Pediatr. 2017;54(2):105-11. doi:10.1007/s13312-017-1010-9

15. Chen C-M, Mu S-C, Chen Y-L, Tsai L-Y, Kuo Y-T, Cheong I-M, et al. Infants' vitamin D nutritional status in the first year of life in Northern Taiwan. Nutrients. 2020;12(2):404.

16. Salameh K, Al-Janahi NSA, Reedy AM, Dawodu A. Prevalence and risk factors for low vitamin D status among breastfeeding mother-infant dyads in an environment with abundant sunshine. Int $\mathrm{J}$ Womens Health. 2016;8:529-35. doi:10.2147/IJWH.S107707

17. Nakano S, Suzuki M, Minowa K, Hirai S, Takubo N, Sakamoto Y, et al. Current vitamin D status in healthy Japanese infants and young children. J Nutr Sci Vitaminol (Tokyo). 2018;64(2):99-105. doi:10.3177/jnsv.64.99

18. Merewood A, Mehta SD, Grossman X, Chen TC, Mathieu J, Holick MF, et al. Vitamin D status among 4-month-old infants in New England: a prospective cohort study: A prospective cohort study. J Hum Lact. 2012;28(2):159-66. doi:10.1177/0890334411434802

19. Said NA, Kamenwa RW, Limbe MS, Okumu MO, Macharia WM. Prevalence of vitamin D deficiency in exclusively breastfed infants at a tertiary healthcare facility in Nairobi, Kenya. Arch Endocrinol Metab. 2020; 64(6):726-34. doi: 10.20945/2359-3997000000281

20. Oktaria V, Graham SM, Triasih R, Soenarto Y, Bines JE, Ponsonby A-L, et al. The prevalence and determinants of vitamin $D$ deficiency in Indonesian infants at birth and six months of age. PLoS One. 2020;15(10):e0239603. doi:10.1371/journal.pone.0239603

21. Gallo S, Comeau K, Vanstone C, Agellon S, Sharma A, Jones G, et al. Effect of different dosages of oral vitamin $D$ supplementation on vitamin $D$ status in healthy, breastfed infants: a randomized trial. JAMA. 2013;309(17):1785-92. doi:10.1001/jama.2013.3404

22. Hollis BW, Wagner CL, Howard CR, Ebeling M, Shary JR, Smith PG, et al. Maternal versus infant vitamin $D$ supplementation during lactation: A randomized controlled trial. Pediatrics. 2015;136(4):625-34. doi: 10.1542/peds.2015-1669.

23. Ziegler EE, Nelson SE, Jeter JM. Vitamin D supplementation of breastfed infants: a randomized doseresponse trial. Pediatr Res. 2014;76(2):177-83. doi:10.1038/pr.2014.76

24. Tan ML, Abrams SA, Osborn DA. Vitamin D supplementation for term breastfed infants to prevent vitamin D deficiency and improve bone health. Cochrane Database Syst Rev. 2020;12:CD013046. doi: 10.1002/14651858.CD013046.pub2. 
25. Huey SL, Acharya N, Silver A, Sheni R, Yu EA, Peña-Rosas JP, et al. Effects of oral vitamin D supplementation on linear growth and other health outcomes among children under five years of age. Cochrane Database Syst Rev. 2020;12:CD012875. doi:10.1002/14651858.CD012875.pub2

26. Pratumvinit B, Wongkrajang P, Wataganara T, Hanyongyuth $S$, Nimmannit A, Chatsiricharoenkul $S$, et al. Maternal vitamin D status and its related factors in pregnant women in Bangkok, Thailand. PLoS One. 2015;10(7):e0131126. doi:10.1371/journal.pone.0131126

27. Dawodu A, Davidson B, Woo JG, Peng Y-M, Ruiz-Palacios GM, de Lourdes Guerrero M, et al. Sun exposure and vitamin $D$ supplementation in relation to vitamin $D$ status of breastfeeding mothers and infants in the global exploration of human milk study. Nutrients. 2015;7(2):1081-93. doi:10.3390/nu7021081

28. Wagner CL, Hollis BW. Early-life effects of vitamin D: A focus on pregnancy and lactation. Ann Nutr Metab. 2020;76 Suppl 2(2):16-28. doi:10.1159/000508422

\section{Tables}

\section{Table 1. Baseline characteristics of study population}




\begin{tabular}{|c|c|c|c|}
\hline Characteristics & $\begin{array}{l}\text { Exclusively breastfed without } \\
\text { vitamin D supplementation } \\
\qquad \begin{array}{c}\text { (control group) } \\
\mathrm{n}=44\end{array}\end{array}$ & $\begin{array}{l}\text { Exclusively breastfed with } \\
\text { vitamin D supplementation } \\
\begin{array}{l}\text { (intervention group) } \\
\mathrm{n}=43\end{array}\end{array}$ & $\begin{array}{c}\mathrm{p}- \\
\text { value }\end{array}$ \\
\hline \multicolumn{4}{|l|}{ Mother } \\
\hline Age, years & $31.1 \pm 4.2$ & $31.3 \pm 5.4$ & 0.84 \\
\hline \multicolumn{4}{|l|}{ Infant } \\
\hline Sex, male & $21(47.7)$ & $16(37.2)$ & 0.32 \\
\hline Inborn & $26(59.1)$ & $22(51.2)$ & 0.46 \\
\hline $\begin{array}{l}\text { Gestational } \\
\text { age, weeks }\end{array}$ & $38 \pm 1$ & $38 \pm 1$ & 0.79 \\
\hline $\begin{array}{l}\text { Small for } \\
\text { gestational age }\end{array}$ & $7(15.9)$ & $6(14.0)$ & 0.80 \\
\hline $\begin{array}{l}\text { Large for } \\
\text { gestational age }\end{array}$ & $1(2.3)$ & $1(2.3)$ & 1.00 \\
\hline Seasons at birth & & & 0.75 \\
\hline $\begin{array}{l}\text { Cool season, Nov- } \\
\text { Feb }\end{array}$ & $20(45.5)$ & $23(53.5)$ & \\
\hline $\begin{array}{l}\text { Hot season, Mar- } \\
\text { Jun }\end{array}$ & $11(25.0)$ & $9(20.9)$ & \\
\hline $\begin{array}{l}\text { Rainy season, Jul- } \\
\text { Oct }\end{array}$ & $13(29.5)$ & $11(25.6)$ & \\
\hline \multicolumn{4}{|l|}{ At birth } \\
\hline Weight, g & $3012 \pm 373$ & $3176 \pm 375$ & 0.05 \\
\hline Length, cm & $49.1 \pm 1.9$ & $49.4 \pm 2.3$ & 0.51 \\
\hline $\begin{array}{l}\text { Head } \\
\text { circumference, cm }\end{array}$ & $33.5 \pm 1.5$ & $33.9 \pm 1.3$ & 0.16 \\
\hline \multicolumn{4}{|l|}{ At enrollment } \\
\hline Weight, g & $4997 \pm 423$ & $5302 \pm 560$ & $<0.01$ \\
\hline Length, cm & $56.6 \pm 2.0$ & $57.5 \pm 1.9$ & 0.93 \\
\hline Head & $38.4 \pm 1.2$ & $38.6 \pm 1.3$ & 0.38 \\
\hline
\end{tabular}


circumference, cm

Data are presented as mean \pm standard deviation or $\mathrm{n}(\%)$.

Table 2. Study results 


\begin{tabular}{|c|c|c|c|}
\hline Characteristics & $\begin{array}{l}\text { Exclusively breastfed } \\
\text { without vitamin D } \\
\text { supplementation (control } \\
\text { group) } \\
\mathrm{n}=44\end{array}$ & $\begin{array}{l}\text { Exclusively breastfed with } \\
\text { vitamin D supplementation } \\
\qquad \begin{array}{c}\text { (intervention group) } \\
\mathrm{n}=43\end{array}\end{array}$ & $\begin{array}{c}\mathrm{p}- \\
\text { value }\end{array}$ \\
\hline \multicolumn{4}{|l|}{ Mother } \\
\hline \multicolumn{4}{|l|}{ Vitamin D levels } \\
\hline $25 \mathrm{OHD}_{2}, \mathrm{ng} / \mathrm{mL}$ & $0.10 \pm 0.38$ & $0.08 \pm 0.37$ & 0.83 \\
\hline $25 \mathrm{OHD}_{3}, \mathrm{ng} / \mathrm{mL}$ & $24.97 \pm 7.77$ & $23.67 \pm 7.70$ & 0.44 \\
\hline $\begin{array}{l}25 \mathrm{OHD} \\
\text { (total), ng/mL }\end{array}$ & $25.08 \pm 7.75$ & $23.75 \pm 7.64$ & 0.42 \\
\hline $\begin{array}{l}\text { Vitamin D } \\
\text { (25OHD) status }\end{array}$ & & & 0.25 \\
\hline $\begin{array}{l}\text { Deficiency, }<12 \\
\mathrm{ng} / \mathrm{mL}\end{array}$ & $1(2.3)$ & $1(2.3)$ & \\
\hline $\begin{array}{l}\text { Insufficiency, 12-20 } \\
\mathrm{ng} / \mathrm{mL}\end{array}$ & $9(20.5)$ & $15(34.9)$ & \\
\hline $\begin{array}{l}\text { Sufficiency, }>20 \\
\mathrm{ng} / \mathrm{mL}\end{array}$ & $34(77.3)$ & $27(62.8)$ & \\
\hline \multicolumn{4}{|l|}{ Infant } \\
\hline \multicolumn{4}{|l|}{ Vitamin D levels } \\
\hline $25 \mathrm{OHD}_{2}, \mathrm{ng} / \mathrm{mL}$ & $0.00 \pm 0.00$ & $0.00 \pm 0.00$ & - \\
\hline $25 \mathrm{OHD}_{3}, \mathrm{ng} / \mathrm{mL}$ & $20.57 \pm 12.66$ & $46.01 \pm 16.42$ & $<0.01$ \\
\hline $\begin{array}{l}25 \mathrm{OHD} \\
\text { (total), } \mathrm{ng} / \mathrm{mL}\end{array}$ & $20.57 \pm 12.66$ & $46.01 \pm 16.42$ & $<0.01$ \\
\hline $\begin{array}{l}\text { Vitamin D } \\
\text { (25OHD) status }\end{array}$ & & & $<0.01$ \\
\hline $\begin{array}{l}\text { Deficiency, }<12 \\
\mathrm{ng} / \mathrm{mL}\end{array}$ & $11(25.0)$ & $0(0.0)$ & \\
\hline $\begin{array}{l}\text { Insufficiency, 12-20 } \\
\mathrm{ng} / \mathrm{mL}\end{array}$ & $14(31.8)$ & $3(7.0)$ & \\
\hline
\end{tabular}




\begin{tabular}{|l|c|c|c|}
$\begin{array}{l}\text { Sufficiency, }>20 \\
\mathrm{ng} / \mathrm{mL}\end{array}$ & $19(43.2)$ & $40(93.0)$ & \\
\hline Serum bone markers & & & \\
\hline Calcium, mg/dL & $10.60 \pm 0.37$ & $5.53 \pm 0.40$ & 0.73 \\
\hline Phosphorous, mg/dL & $5.47 \pm 0.45$ & $242.79 \pm 58.54$ & 0.54 \\
\hline ALP, U/L & $250.41 \pm 59.71$ & $16.3(12.1-23.5)$ & 0.13 \\
\hline iPTH, pg/mL & $19.45(10.85-34.35)$ & & \\
\hline $\begin{array}{l}\text { Physical growth } \\
\text { parameters }\end{array}$ & & & 0.32 \\
\hline$\Delta$ Weight, g & $2059 \pm 545$ & $8.6 \pm 1.5$ & 0.94 \\
\hline$\Delta$ Length, cm & $8.5 \pm 1.4$ & $4.0 \pm 1.0$ & 0.70 \\
\hline $\begin{array}{l}\Delta \text { Head } \\
\text { circumference, cm }\end{array}$ & $4.0 \pm 0.8$ & & \\
\hline
\end{tabular}

Data are presented as mean \pm standard deviation, $\mathrm{n}(\%)$, or median (interquartile range). $\Delta$ represents the increment in each parameter from 2 to 6 months. $25 \mathrm{OHD}_{2}, 25$-hydroxyvitamin $\mathrm{D}_{2} ; 25 \mathrm{OHD}_{3}, 25$-hydroxyvitamin $\mathrm{D}_{3} ; 25 \mathrm{OHD}$, total 25-

hydroxyvitamin D; ALP, alkaline phosphatase; iPTH, intact parathyroid hormone

Table 3. Prediction of serum bone markers at serum $250 H D$ concentration of $\leq 20 \mathrm{ng} / \mathrm{mL}$

\begin{tabular}{|l|c|c|}
\hline Serum bone markers & Beta (95\% confidence interval) & $\mathrm{p}$-value \\
\hline Calcium & $-0.099(-0.255-0.056)$ & 0.208 \\
\hline Phosphorous & $-0.149(-0.343-0.045)$ & 0.129 \\
\hline ALP & $13.899(-13.026-40.724)$ & 0.308 \\
\hline iPTH & $13.724(4.160-23.288)$ & 0.005 \\
\hline
\end{tabular}

ALP, alkaline phosphatase; iPTH, intact parathyroid hormone

\section{Figures}




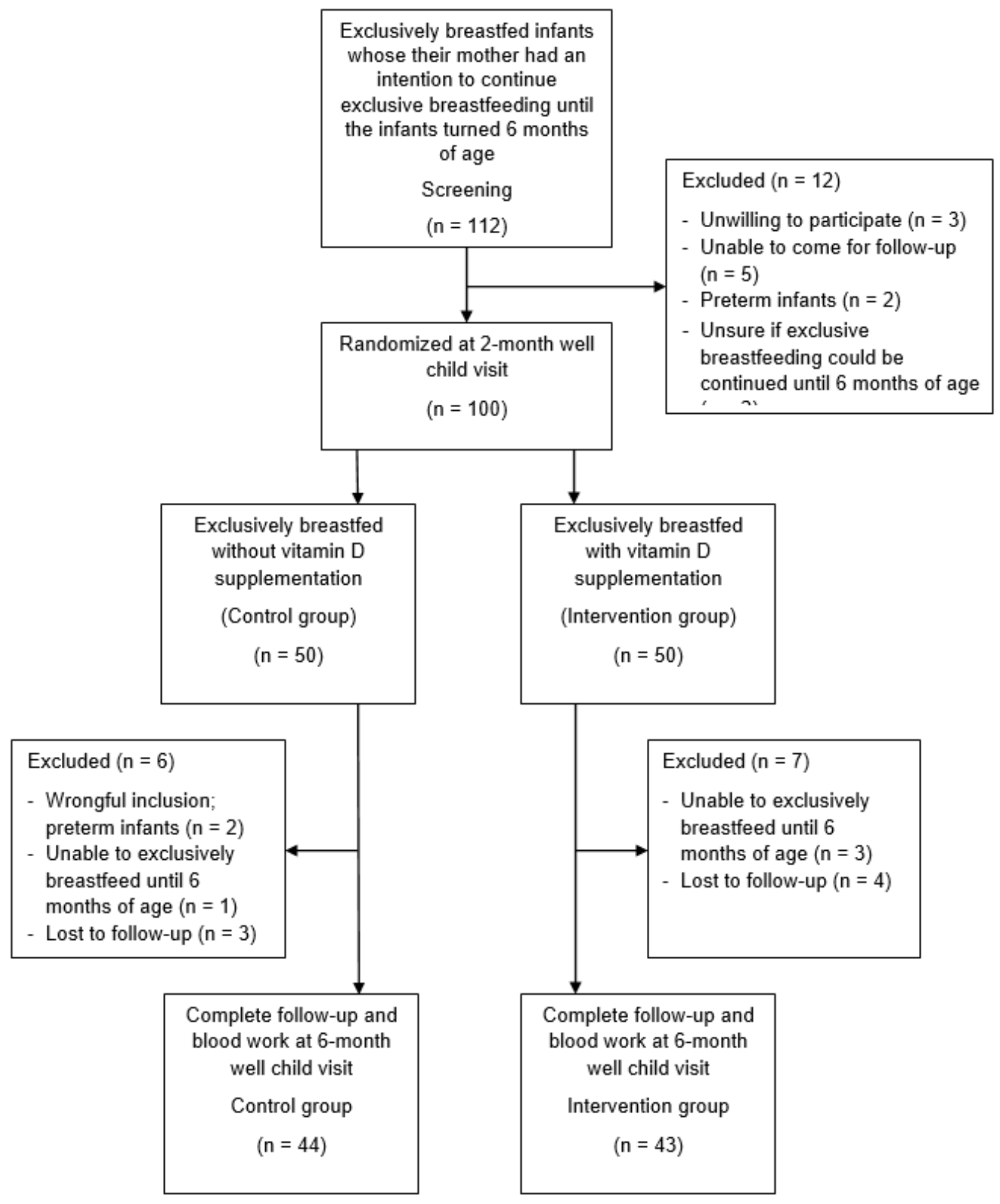

\section{Figure 1}

Flow chart of study participants 